\title{
A Mineralogia e alguns de seus minerais raros ou de gênese exótica
}

\author{
Pércio de Moraes Branco \\ CPRM - Serviço Geológico do Brasil \\ Porto Alegre-RS \\ pmbranco@pa.cprm.gov.br
}

Mario Luiz de Sá Carneiro Chaves

Centro de Pesquisas Prof. Manoel Teixeira da Costa

Instituto de Geociências - Univ. Federal de Minas Gerais

Pesquisador CNPq

mchaves@igc.ufmg.br

* Este documento deve ser referido como segue:

Branco P.M., Chaves M.L.S.C. 2006. A Mineralogia e alguns de seus minerais raros ou de gênese exótica. Terræ Didatica, 2(1):75-85. <http:// www.ige.unicamp.br/ terraedidatica/>

\begin{abstract}
RESUMO O estudo da gênese dos minerais envolve um amplo espectro com mais de 4.000 espécies válidas, podendo apresentar aspectos especiais e únicos, na medida em que grande parte dessas espécies constitui raridades, e algumas em particular possuem um modo de formação inteiramente exótico. Por exemplo, existem minerais de formação sazonal, aparecendo em estações secas e logo depois destruídos nas épocas úmidas; ou minerais formados pela oxidação de amostras de material carbonático, somente quando o mesmo encontra-se guardado dentro de caixas de madeira; ou originados pela reação de serpentinitos com certo líquen desenvolvido em suas superfícies; ou ainda formados pela ação da água sobre objetos de estanho afundados junto com uma canoa. Esses casos, do mesmo modo que outros mostrados neste trabalho, demonstram a possibilidade de existência de condições ambientais que são muito distintas das usualmente encontradas na natureza.
\end{abstract}

PALAVRAS-CHAVE Mineralogia, minerais raros, mineralogênese

ABSTRACT Mineralogy, rare minerals, and species of exotic genesis. The knowledge of the mineral genesis includes a large list with over than 4.000 valid species, can present some special aspects which made those processes different of the normal ones. There are, for instance, seasonal mineral species, which appear in dry seasons and are destructed in wet epochs; or minerals formed by oxidation of carbonatic material samples, only when stored within wooden cases; or a species that is formed by reaction between serpentinite and a licken developed on its surface; or other, whose formation begun since a centennial ship sunk in a river, by water action on tin tools. Such examples, related with others in this paper, show mineral genesis in which time and environmental conditions are quite different of those usually found.

KEYWORDS Mineralogy, rare minerals, mineralogenesis 


\section{Introdução}

A Mineralogia, como parte das geociências que trata dos minerais, abrange um universo de mais que 4.000 espécies distintas, número este que vem crescendo a cada ano em 40-50 novas espécies. Nesse vasto contexto, somente cerca de $10 \%$ dessas espécies ocorrem de modo mais abundante na crosta terrestre, de tal forma que a grande maioria delas é constituída de raridades ou mesmo espécies de origem extremamente incomum. $\mathrm{Na}$ formação de alguns desses minerais interferem variáveis tão particulares que determinam processos bastante diferentes dos modelos genéticos usualmente encontrados na natureza, o que certas vezes pode tornar questionável a inclusão do produto final como uma espécie mineral válida. Tais variáveis podem ir desde a simples presença de matéria orgânica em determinado ambiente, até um acontecimento fortuito e imprevisível como o naufrágio de uma embarcação carregada com objetos confeccionados em estanho.

Constitui objetivo deste trabalho o relato de diversos desses casos que mostram como a combinação de processos inorgânicos com a ação antrópica ou com a presença de matéria orgânica animal/vegetal, pode resultar na formação de espécies minerais incomuns. Outro caso absolutamente exótico, cuja origem permanece como um enigma para a ciência, é o modo de formação da variedade carbonado do diamante, na realidade um agregado de microdiamantes. Entretanto, deve-se salientar que por mais insólitas sejam as circunstâncias envolvidas nos processos da gênese dos minerais aqui abordados, todos os produtos finais obtidos a partir de tais processos são considerados como espécies válidas pela International Mineralogical Association (IMA). Deve-se salientar que os limites da definição de um mineral encontram-se atualmente estabelecidos em Nickel e Grice (1998).

\section{Minerais raros - os "minerais comuns"}

Conforme pode ser observado nos modernos compêndios mineralógicos (eg., Nickel e Nichols 1991, Mandarino e Back 2004), a imensa maioria das espécies minerais comuns ao meio geocientífico encontra-se envolvida em meio a tantas outras espécies de nomes invulgares e modos de formação parcial ou inteiramente desconhecidos. O grande número desses minerais raros, muitos deles aparecendo somente em um local de ocorrência, tem feito com que a própria utilidade da Mineralogia tenha já sido questionada. Certamente a maior parte de tais espécies foi descrita ao longo dos últimos 40 anos, com as facilidades que resultaram do uso rotineiro e acadêmico da microssonda eletrônica. Não obstante a existência do questionamento citado, essas descobertas podem ter desdobramentos úteis tendo em vista outras aplicações na evolução do conhecimento científico.

Das 40 a 50 novas espécies minerais descritas a cada ano, a grande maioria ocorre somente em grãos muito finos, a maior parte das vezes em escala submilimétrica, bem como em quantidades ínfimas. Além disso, tais espécies normalmente não possuem qualquer importância nos processos petrogenéticos. Pring (1994), discutiu a questão, realçando que a descrição de um novo mineral necessita de uma razoável síntese de dados que abrange uma listagem ampla de métodos experimentais, modernos e/ou clássicos. Contudo, apesar de tal trabalho requerer um considerável esforço intelectual e científico, uma certa parcela da classe geocientífica parece considerar tal esforço de pouca utilidade prática. Segundo Pring (1994) uma das razões para tal descrédito, é o fato de ser muito difícil desenvolver um programa de pesquisa de longo prazo, onde o objetivo central é a descrição de um ou mais minerais. Desta forma, levando-se ainda em conta de que a descrição de um novo mineral em geral se associa a um certo fator de casualidade, não constitui prioridade básica para uma agência de fomento científico fornecer apoio a projetos semelhantes.

Ao mesmo tempo, os estudiosos da Mineralogia, podem também ser em parte considerados responsáveis pela pouca estima a que a disciplina foi relegada. Em geral, existe a tendência de considerar os minerais somente em termos químicomineralógicos, e não mostrá-los como um produto resultante de processos de formação de materiais inorgânicos. Afinal, minerais são componentes inorgânicos de ocorrência natural, e alguns desses minerais podem ser ainda novos compostos inorgânicos. Tais compostos possivelmente incluem propriedades físicas características - eletrônicas, ópticas ou magnéticas - passíveis de aplicações tecnológicas. Em conseqüência, entre os novos minerais descritos a cada ano certos deles devem também possuir propriedades de interesse tecnológico (Pring 1994). 
Exemplos bastante recentes, que ilustram o enfoque anteriormente citado, são os das descobertas da coutinhoíta e da lindbergita por pesquisadores da Universidade de São Paulo (Atencio et al. 2004a, 2004b) e de suas possíveis aplicações (Atencio 2004). Ambos os minerais foram descritos a partir de amostras provenientes de lavras em pegmatitos de Galiléia, a leste de Governador Valadares (Minas Gerais). A coutinhoíta, um silicato hidratado de Th-uranila, tem importância não só como mineral de urânio, como também para aplicações ambientais em jazidas que explorem esse elemento químico. Os silicatos de uranila (eg., uranofânio, haiweeíta, weeksita etc.) são normalmente abundantes em depósitos de lixo nuclear, devido à alteração de combustível nuclear e vidro de composição borossilicática, em presença de sílica que é derivada das rochas hospedeiras desses depósitos. Deste modo, o conhecimento da estrutura cristalina dos silicatos de uranila pode ser a chave para entender-se o desempenho, a longo prazo, de um repositório para lixo nuclear (Jackson e Burns 2001, in Atencio 2004).

A lindbergita é um oxalato de manganês diidratado (Atencio et al. 2004b). O estudo de oxalatos pouco solúveis está relacionado ao seu uso como precursores na síntese de materiais cerâmicos supercondutores a altas temperaturas, bem como à preparação de nanomateriais e inúmeros outros novos materiais, devido aos processos de precipitação propiciarem o controle das propriedades físicas e químicas dos produtos finais (Atencio 2004). Além disso, os sistemas oxálicos são também tradicionalmente usados para a separação e concentração de certos elementos, especialmente terras raras e transurânicos (Donkova et al. 2004, in Atencio 2004).

\section{Minerais de gênese exótica}

Nesta síntese, serão relatados os modos de formação de diversos minerais, nem todos de descoberta recente, os quais envolvem processos inusitados e pouco conhecidos até mesmo no meio acadêmico das geociências. As fórmulas químicas, juntamente com os sistemas cristalinos fornecidos, estão de acordo com a relação oficial da International Mineralogical Association (Mandarino e Back 2004). Os minerais serão apresentados em ordem não rigorosa, procurando descrever de início os que se desenvolvem com ligação direta ou indireta a seres vivos, passando aos sazonais e pelos que se formam pela alteração de outros materiais (orgânicos ou inorgânicos), até os que podem se cristalizar sob condições extracrosta terrestre ou mesmo extraterrestre.

\section{Fairchildita e bütschliíta $-\mathrm{K}_{2} \mathrm{Ca}\left(\mathrm{CO}_{3}\right)_{2}$ - hexagonal e trigonal}

Em certos locais do sudoeste norte-americano (Kaniksu National Forest, Bonner, Idaho e Grand Canyon National Park, Coconino, Arizona), desde a década de 1920 se tem observado que muitas árvores queimadas, principalmente abetos e cicutas, contêm presas em seus troncos algumas "pedras" de tamanhos e quantidades variáveis, apresentando uma cor branca e estrutura fibrosa (Milton e Axelrod 1947). No entanto, enquanto diversas dessas árvores continham somente umas poucas de tais "pedras", outras mostravam dezenas de quilos do material. E ainda, se em algumas elas mediam poucos centímetros, em outras tinham quase $50 \mathrm{~cm}$ de diâmetro. Constatou-se também que as árvores queimadas depois de já estarem caídas e nos troncos onde o fogo só atingia zonas acima de uma certa porção apodrecida, não mostravam aquele material estranho. Tais fatos indicam ser necessário que a árvore estivesse viva, à época em que ocorreu a queima, para a formação de tal material.

Diversas hipóteses foram logo apresentadas para explicar a origem daquelas substâncias, tais como doença das árvores, excessiva evaporação de seiva, fusão de cinzas por ação de raios e fusão de calcário. Uma outra hipótese, apresentada com grande repercussão na imprensa da época, dizia que tais "pedras" poderiam ser meteoritos e que a queda dos mesmos teria provocado a combustão da madeira. Analisando-se a questão, raios ou meteoritos dificilmente explicariam a freqüência com que tais "pedras" eram encontradas. De outro modo, doenças ou excessiva evaporação de seiva não explicariam facilmente sua presença em algumas árvores e total ausência em outras da mesma espécie e região. Por último, a fusão de calcário não poderia explicar, por exemplo, a presença de exemplares de grande tamanho nas partes mais altas de uma árvore.

Milton e Axelrod (1947) ao estudarem o material, verificaram tratar-se de dois carbonatos de potássio e cálcio, de mesma composição mas com estruturas cristalinas distintas - hexagonal e trigonal - até então desconhecidos na natureza. Além desses dois carbonatos, calcita também foi identificada como constituinte essencial do material analisado. 
Tais autores verificaram ainda que o material continha inclusões de carvão vegetal ou áreas carbonáceas escuras, bem como estruturas fluidais e cavidades arredondadas, possivelmente formadas pela ação de gases. A partir desses indícios, concluíram que as substâncias se formavam por combustão das árvores e posterior cristalização das cinzas. Eles determinaram também que inicialmente se cristalizou o carbonato hexagonal, que chamaram de fairchildita, o qual, por ação da umidade do ar, transformou-se na forma trigonal, designada de bütschliíta. Por lixiviação posterior desses minerais, formou-se ainda a calcita.

\section{Flagstaffita - $\mathrm{C}_{10} \mathrm{H}_{22} \mathrm{O}_{3}$ - ortorrômbico}

A flagstaffita é uma terpina hidratada que forma pequenos cristais incolores de peso específico 1,09, fortemente piroelétricos (Strunz e Contag 1965). Os cristais, descritos a primeira vez em 1920, no Arizona (EUA), medem 1,0 x 1,5 mm, têm dureza muito baixa e ponto de fusão entre 99 e $100,5^{\circ} \mathrm{C}$. Reagindo com ácido sulfúrico, o mineral dá uma forte solução de cor laranja-amarela, sendo ainda muito solúvel em álcool e benzeno quentes, menos solúvel em éter e insolúvel em água. Seu processo de formação tem algumas semelhanças com aqueles da fairchildita e da bütschliíta. Como esses dois minerais, a flagstaffita ocorre em fendas radiais de troncos de uma espécie de pinheiro americano, onde forma drusas tomando, às vezes, aspecto de delgados veios maciços.

A diferença principal no seu processo de formação está no fato de que os troncos onde a flagstaffita se formou estiveram soterrados por material coluvionar após a queima das árvores. Esse soterramento teve uma duração de pelo menos 500 anos, conforme se verificou pelo estudo das árvores atuais da região. Posteriormente, os troncos afloraram pela remoção do colúvio devido à ação das águas superficiais. Segundo Guild (1920, in Strunz e Contag 1965), o modo de ocorrência e a associação com resina vegetal parecem mostrar de modo claro que o mineral deriva de algum processo de oxidação ou hidratação, possivelmente a partir de resinas naturais das próprias árvores.

$$
\begin{aligned}
& \text { Whewellita - } \mathrm{Ca}\left(\mathrm{C}_{2} \mathrm{O}_{4}\right) \cdot \mathrm{H}_{2} \mathrm{O}-\text { monoclínico } \\
& \text { Weddellita }-\mathrm{Ca}\left(\mathrm{C}_{2} \mathrm{O}_{4}\right) \cdot 2 \mathrm{H}_{2} \mathrm{O} \text { - tetragonal }
\end{aligned}
$$

Os cálculos são concreções inorgânicas (principalmente sais de cálcio, fósforo e amônio) ou mais raramente orgânicas (como ácido úrico, aminoácidos e sulfas), originadas principalmente no aparelho urinário de certos animais. $\mathrm{O}$ mecanismo de formação dos mesmos na maioria das vezes é difícil de ser estabelecido, pois embora certas doenças possam explicar sua presença, nem sempre ela é devida a fenômenos patológicos. Gibson (1974), analisando 15.000 amostras desse material, mostrou que os minerais mais comuns nessas concreções são oxalatos de cálcio (whewellita e weddellita), fosfatos de cálcio (apatita, brushita e whitlockita) e fosfatos de magnésio (struvita e newberyíta). No mesmo estudo, foram ainda identificados aragonita, calcita, gipsita, halita, hannayíta, hexaidrita, monetita e vaterita, de ocorrências esporádicas. Desses minerais, merecem especial atenção a whewellita e a weddellita porque, embora sejam comuns nos cálculos, onde ocorrem associados, são muito raros em ambientes geológicos.

A whewellita mostra hábito predominantemente botrioidal ou globular, com estrutura radial,
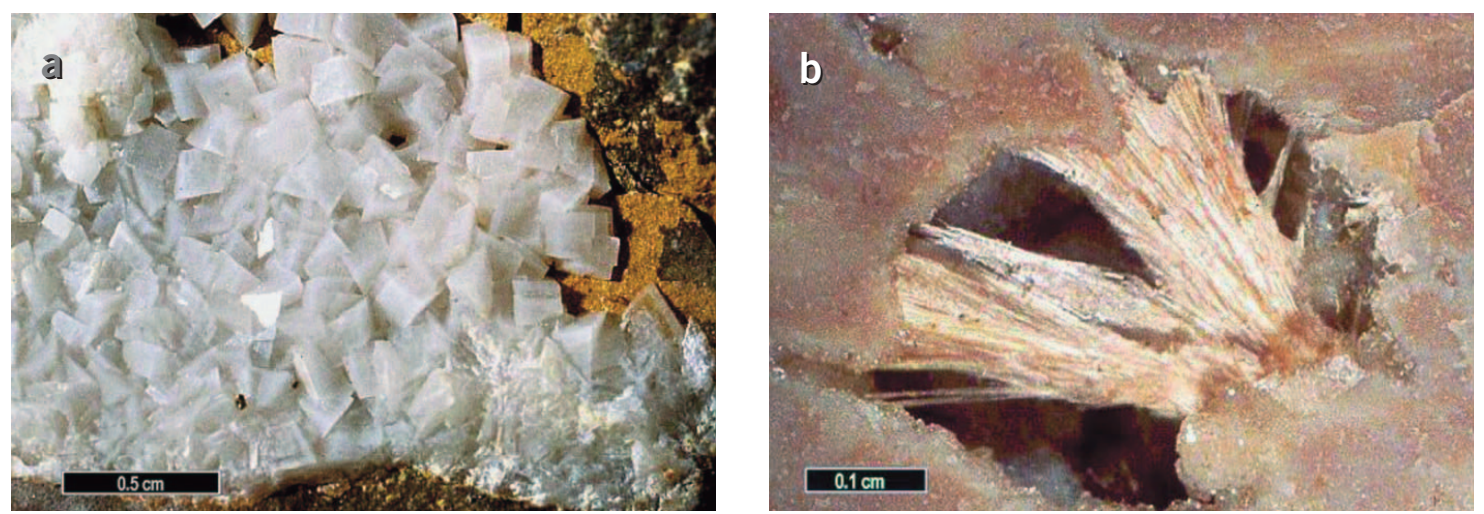

Figura 1 - Fotos ilustrativas de minerais que ocorrem em cálculos renais, (a) whewellita (República Tcheca) e (b) weddelita (EUA). Fotos de Weissman e Nikischer (1999) 
em geral de cores marrom e verde-oliva, podendo ser amarelada até preta, dependendo do teor de matéria orgânica (Fig. 1a). Quando se deposita nas papilas renais (pequenas protrusões dentro dos rins), quase sempre tem um núcleo relativamente pequeno constituído pelos fosfatos de cálcio apatita, brushita ou whitlockita. A weddellita ocorre de modo típico na forma de cristais bipiramidados tetragonais ou agregados de cristais simples, transparentes e sem clivagem (Sterling 1965). Tem dureza em torno de 4, peso específico 1,94 e fratura conchoidal (Fig. 1b). As cores variam de amarelo a branco ou incolor, refletindo também, como no caso da whewellita, diferentes porcentagens de matéria orgânica.

\section{Glushinskita - $\mathrm{Mg}\left(\mathrm{C}_{2} \mathrm{O}_{4}\right) \cdot 2 \mathrm{H}_{2} \mathrm{O}-$ monoclínico}

A glushinskita forma cristais muito pequenos (2-5 mm), piramidais distorcidos, freqüentemente com faces curvas e estriadas (Fig. 2a). Seu modo de ocorrência é bastante original, pois é encontrado na interface rocha-líquen de um serpentinito do nordeste da Escócia, sobre o qual o líquen se desenvolveu (Wilson et al. 1980). Os líquens são organismos resultantes da associação simbiótica entre cogumelos filamentosos e algas clorofíceas (mais raramente cianofíceas) unicelulares, formando um único talo. É uma associação bastante íntima que permite a ambos os indivíduos viverem em locais onde nenhum dos dois teria condições de sobrevivência se isolados. O conjunto de filamentos entrelaçados designa-se de hifa. A glushinskita ocorre exatamente na hifa do líquen Lecanora atra, onde aparece formando uma camada branco-cremosa. Sua formação resulta da reação do ácido oxálico excretado pelo líquen com minerais magnesianos do serpentinito. Processo semelhante foi descrito também sobre basaltos, onde o ácido oxálico do líquen Pertusaria corallina decompõe a labradorita, resultando em oxalato de cálcio cristalino (Wilson e Jones 1984).

\section{Struvita - $\left(\mathrm{NH}_{4}\right) \mathrm{Mg}\left(\mathrm{PO}_{4}\right) \cdot 6 \mathrm{H}_{2} \mathrm{O}$ - ortorrômbico Sasaíta - (Al,Fe $)_{6}\left(\mathrm{PO}_{4}, \mathrm{SO}_{4}\right)_{5}(\mathrm{OH})_{3} \cdot 35 \mathrm{H}_{2} \mathrm{O}$ - ortorrômbico}

A oxidação de material orgânico proveniente de excrementos de morcegos no interior de cavernas leva à formação de vários íons, como o $\left(\mathrm{PO}_{4}\right)^{3-}$. $\mathrm{A}$ água que lixivia a matéria orgânica geralmente é
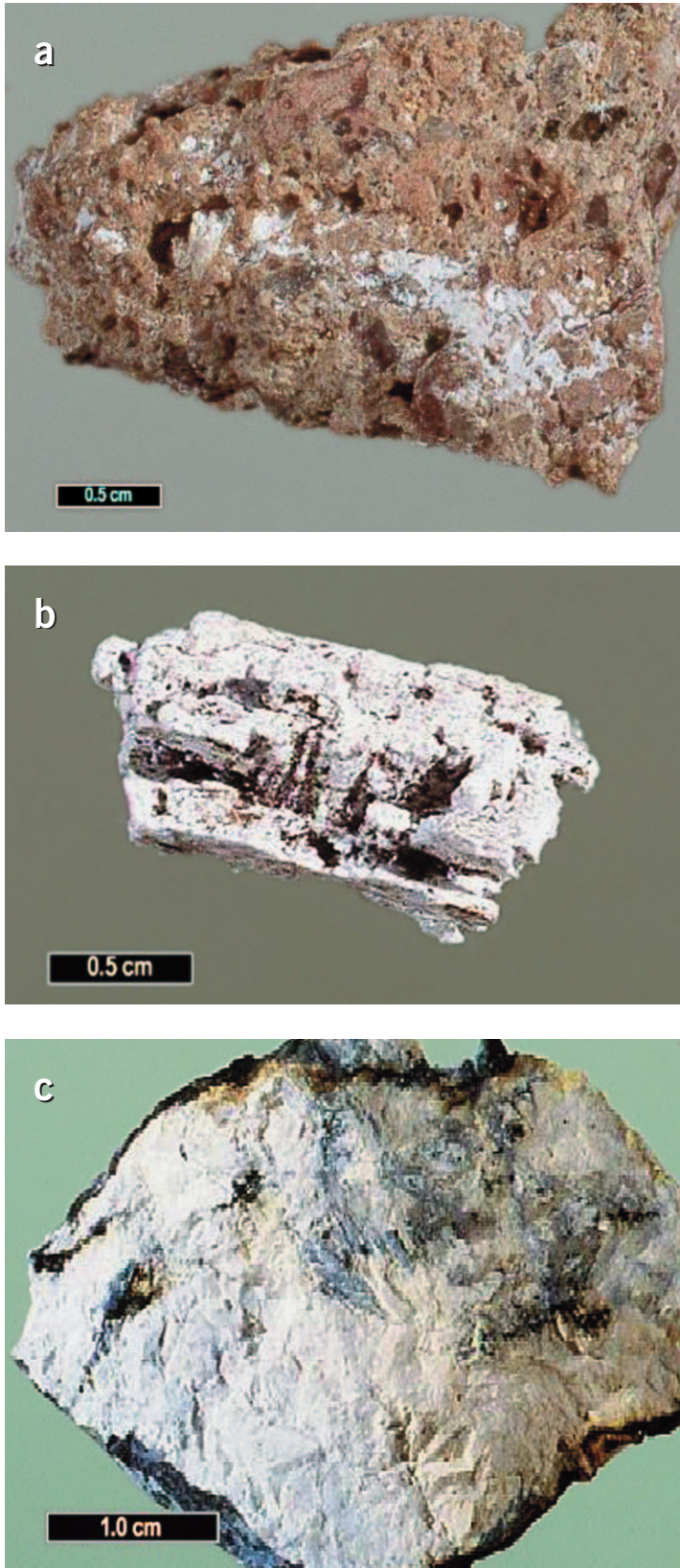

Figura 2 - Fotos ilustrativas de minerais que ocorrem associados a liquens, (a) glushinskita (EUA), ou a excrementos de animais, (b) struvita (Austrália) e (c) sasaíta (Áustria). Fotos de Weissman e Nikischer (1999)

muito ácida, reagindo com minerais argilosos do solo da caverna, originando alguns fosfatos comuns como apatita e variscita, além de outros mais raros como leucofosfita, strengita, fosfossiderita e struvita. Por outro lado, minerais como sasaíta, montgomeryíta, hannayíta, crandallita, brushita, gipsita e óxidos de manganês, embora também possam ser encontrados em cavernas, originando-se do guano 
dos morcegos, não aparecem no solo mas no próprio guano ou sobre espeleotemas.

A struvita, um fosfato hidratado de amônio e magnésio (Whitaker e Jeffery 1970), é incolor ou amarela, de brilho vítreo e constituição frágil, com dureza próxima de 2 e peso específico 1,74 (Fig. 2b). É transparente a translúcida, piroelétrica e piezoelétrica. Ocorre não apenas no guano, mas também em cálculos renais. Foi descoberta debaixo de uma velha igreja construída sobre uma turfeira, em Hamburgo (Alemanha). Depois, foi encontrada em um depósito de esterco bovino e em dentes de mamute no Yukon (Canadá). A struvita se forma em locais onde soluções de magnésia agiram sobre um fosfato na presença de amônia, processo que pode ter lugar, por exemplo, em depósitos de guano que permaneceram longo tempo sem sofrer perturbações.

A sasaíta, um dos minerais que se formam em cavernas, foi descoberta a partir do guano de morcegos (Fig. 2c). No fim da década de 1970, membros da South African Speleological Association (SASA), examinando o interior de uma caverna em dolomito, em West Driefontein, no Transvaal (República Sul-Africana), observaram a existência de nódulos brancos de até $2 \mathrm{~cm}$ no solo, com consistência de giz, formados de uma substância que podia ser encontrada também como eflorescências e em gretas de ressecamento. Posterior exame mineralógico e químico do material mostrou que se tratava de uma espécie mineral nova, denominada sasaíta em homenagem àquela associação (Martini 1978). O mineral é um fosfato-sulfato básico hidratado de alumínio e ferro, que cristaliza em placas de 0,01-0,02 mm, com peso específico 1,75. Se colocado em atmosfera saturada em água, se reidrata totalmente em duas semanas.
Hidrocloroborita $-\mathrm{Ca}_{2} \mathrm{~B}_{4} \mathrm{O}_{4}(\mathrm{OH})_{7} \mathrm{Cl} \cdot 7 \mathrm{H}_{2} \mathrm{O}$ - monoclínico

$$
\begin{aligned}
& \text { Sinjarita }-\mathrm{CaCl}_{2} \cdot 2 \mathrm{H}_{2} \mathrm{O}-\text { tetragonal } \\
& \text { Antarcticita }-\mathrm{CaCl}_{2} \cdot 6 \mathrm{H}_{2} \mathrm{O}-\text { trigonal } \\
& \text { Acetamida }-\mathrm{CH}_{3} \mathrm{CO} \cdot \mathrm{NH}_{2}-\text { trigonal }
\end{aligned}
$$

A hidrocloroborita, um cloro-borato de cálcio, foi descoberta em 1965 em algum local não especificado da China e descrita em periódico local (Ch'ien e Chen 1965, in Hurlbut Jr. et al. 1977). Ela se apresenta em cristais euédricos incolores de até $13 \mathrm{~mm}$, com clivagem basal perfeita, dureza 2,5 e peso específico 1,9 (Fig. 3a). Em 1966, foi reportada uma segunda ocorrência na localidade de Salar Carcote, em Antofagasta (Chile), onde os cristais apareciam em uma camada contínua e irregular com cerca de $15 \mathrm{~cm}$ de espessura. Entretanto, Hurlbult Jr. et al. (1977) ao procurarem depois o mineral naquela localidade, não o acharam. Esses autores verificaram que o nível freático estava apenas $15 \mathrm{~cm}$ abaixo da camada que continha o mineral, cota superior à da época em que o mesmo havia sido descrito de início. Esse fato demonstrou que a hidrocloroborita é um mineral sazonal, que se dissolve nas estações úmidas, voltando a cristalizar em estações secas.

Vários outros minerais se formam sazonalmente. Um deles é a sinjarita, um cloreto hidratado de cálcio granular, que aparece como cristais prismáticos alongados, rosa-claros, de brilho vítreo a resinoso, e com dureza muito baixa $(1,5)$. Esse mineral foi descrito por Aljubouri e Aldabbagh (1980), no leito seco de um rio intermitente de Sinjar (Iraque), onde precipitou em sedimentos recentes por evaporação lenta de água subterrânea saturada em $\mathrm{Ca}^{2+}$ e $\mathrm{Cl}^{-}$. Como tal substância é altamente
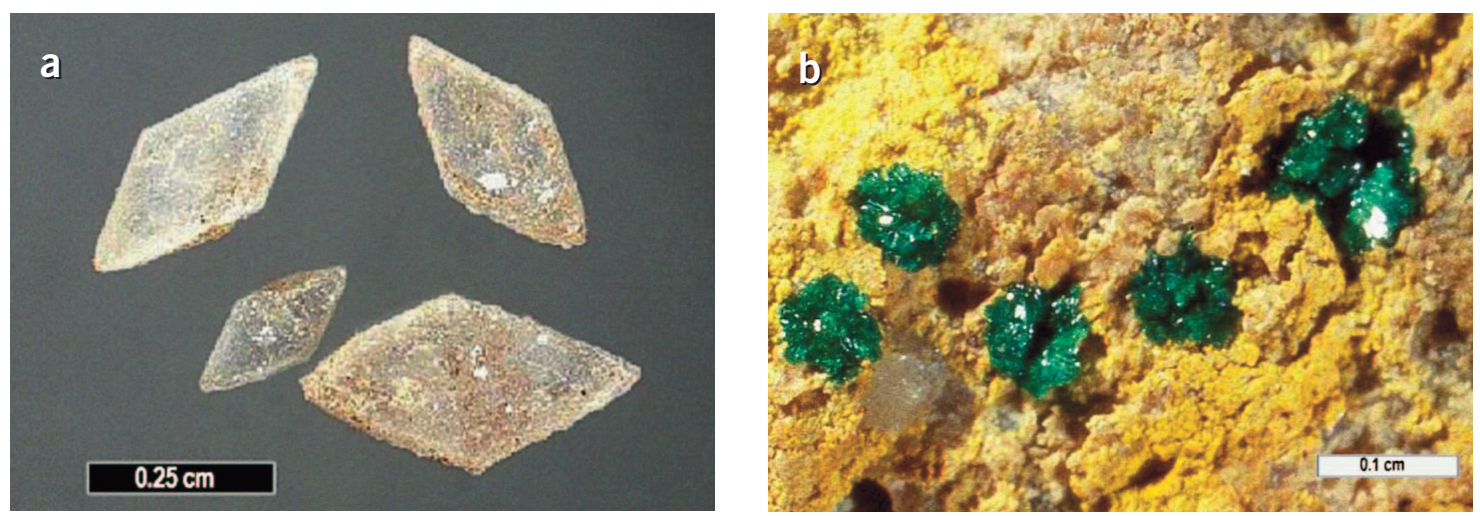

Figura 3 - Fotos ilustrativas de minerais de ocorrência sazonal, (a) hidrocloroborita (Antofagasta, Chile), ou formados pela corrosão de outros materiais, como a (b) paratacamita (Austrália). Fotos de Weissman e Nikischer (1999) 
higroscópica, ela pode exibir diferentes graus de hidratação. A antarcticita (descoberta na Terra de Vitória, continente antártico) constitui uma forma mais hidratada, que funde a $30^{\circ} \mathrm{C}$ e, por isso, é destruída nas estações secas, caso a temperatura atingir aquele valor (Torii e Ossaka 1965). Formas menos hidratadas que a antarcticita e mais hidratadas que a sinjarita são conhecidas sinteticamente, mas ainda não foram encontradas na natureza.

Outro interessante mineral sazonal é a acetamida, uma amida cristalina derivada do ácido acético (Shebrodol'skii 1975, Fleischer et al. 1976). Esse mineral forma cristais de até $5 \mathrm{~mm}$, incolores ou cinza (devido à matéria orgânica), com dureza 1,0-1,5, peso específico 1,2 e fratura conchoidal. Foi descoberto em rejeitos de uma mina de carvão da antiga URSS, onde se formou durante estações secas em áreas enriquecidas em amônia e isoladas do contato com oxigênio e luz solar. Se exposto ao sol, o mineral volatiliza-se em algumas horas.

$$
\begin{aligned}
& \text { Calclacita }-\mathrm{Ca}\left(\mathrm{CH}_{3} \mathrm{COO}\right) \mathrm{Cl} \cdot 5 \mathrm{H}_{2} \mathrm{O}-\text { monoclínico } \\
& \text { Embreyíta }-\mathrm{Pb}_{5}\left(\mathrm{CrO}_{4}\right)_{2}\left(\mathrm{PO}_{4}\right)_{2} \mathrm{H}_{2} \mathrm{O}-\text { monoclínico }
\end{aligned}
$$

A calclacita, um cloreto-acetato de cálcio, costuma surgir como eflorescências sobre rochas calcárias, fósseis e peças de cerâmica guardadas em museus (Tassel 1958). O interesse na origem desse mineral é que ele só se forma se os materiais carbonáticos ou a cerâmica estiverem acondicionados em caixas de madeira; caso estiverem guardadas em recipientes de vidro, por exemplo, as eflorescências não se desenvolvem, indicando que o ácido acético necessário à sua formação é proveniente da madeira.

Alguns outros minerais se formam também a partir de peças de museus. Pirita e marcassita encontradas como concreções ou preenchendo fissuras em camadas de carvão de Santa Catarina, podem sofrer oxidação quando trazidas para a superfície, formando sulfatos em poucos meses. Um testemunho de sondagem de siltito com pequena lâmina de pirita da coleção de um dos autores (PMB), oito meses após a conclusão do furo onde foi obtido mostrava um "tufo" extremamente delicado com cerca de $2 \mathrm{~cm}$ de altura, constituído de um sulfato do grupo da halotriquita.

Outro exemplo afim é a embreyíta (Williams 1972), um mineral alaranjado, fosco e quebradiço, apresentando dureza baixa $(3,5)$. Esse fosfatocromato hidratado de chumbo, foi descrito originalmente sobre antigas amostras do museu de Berezov, na região da Sibéria (Rússia).

\section{Mackinawita - FeS - tetragonal \\ Paratacamita - $\mathrm{Cu}_{2} \mathrm{Cl}(\mathrm{OH})_{3}$ - trigonal}

A mackinawita é um sulfeto de ferro, sempre com alguma quantidade variável de níquel, ainda pouco estudado. Certos autores, inclusive, incluem o níquel na composição química do mineral ( $\mathrm{Fe}, \mathrm{Ni})_{9} \mathrm{~S}_{8}$ (Nickel e Nichols 1991), o que não é referendado pela International Mineralogical Association (IMA). Esse material já havia sido descrito junto com ligas metálicas em meteoritos, mas foi encontrado também fora desse ambiente na mina de Snohomish, em Mackinaw (daí seu nome), Washington (EUA), onde se formou pela corrosão bacteriana de chaminés e canos de ferro (Evans et al. 1962). Analisando o trabalho dos autores que "descobriram" o mineral, Fleischer (1963) julgou serem os dados apresentados como insuficientes para caracterizá-lo como uma espécie nova. Todavia, o mineral foi aprovado pela IMA.

A paratacamita é um hidroxicloreto de cobre (Fig. 3b), constituindo uma série isomórfica com a atacamita (ortorrômbica) e a botallackita (monoclínica). O mineral, originalmente descrito em $1906 \mathrm{em}$ amostras provenientes das minas Herminia e Generosa, em Sierra Gorda (Chile), foi reconhecido como uma espécie diferente da atacamita por Frondel (1950, in Fleet 1975). Fleet (1975) definiu a estrutura cristalina do mineral. Ele tem cor verde, brilho vítreo, sendo translúcido a quase opaca, com fratura conchoidal a irregular, dureza 3,0 e peso específico 3,7. Embora se forme comumente pela alteração da nantokita $(\mathrm{CuCl}), \mathrm{da}$ eriocalcita $\left(\mathrm{CuCl}_{2} 2 \mathrm{H}_{2} \mathrm{O}\right)$ e da tenorita $(\mathrm{CuO})$, pode-se formar também por um outro processo, muito semelhante ao que origina a mackinawita. Assim, a corrosão do cobre, bronze ou latão, usados na fabricação de objetos antigos que estiveram submetidos à ação de ar salino, leva ao surgimento de uma pátina ou crosta pulverulenta sobre aqueles objetos, de cor verde, constituída de paratacamita.

\section{Romarchita - SnO - tetragonal \\ Hidrorromarchita - $\mathrm{Sn}_{3} \mathrm{O}_{2}(\mathrm{OH})_{2}$ - tetragonal}

Dois minerais de origens absolutamente insólitas são os óxidos de estanho romarchita (pronuncia-se romarquita) e a hidrorromarchita (Organ e Mandarino 1971). Entre 1801 e 1821, uma canoa que levava utensílios constituídos de 
estanho afundou no rio Winnipeg, em Ontário, Canadá. Aqueles objetos ficaram submersos desde aquela data até o início da década de 1970, quando foram recuperados a uma profundidade de $4,5 \mathrm{~m}$. Ao serem retirados da água, verificou-se que continham em sua superfície uma crosta fina de cristais brancos, aos quais se associavam outros cristais, de cor preta. O estudo do material mostrou tratar-se de dois novos minerais, designados de romarchita (o preto) e hidrorromarchita (o branco). As circunstâncias estranhas que deram origem à formação dessas espécies geraram controvérsias no âmbito da IMA, onde alguns membros da comissão que aprova novos minerais julgaram não serem espécies válidas. Entretanto, submetido o assunto a votação, elas foram aprovadas pela associação, por dez votos contra quatro.

$$
\begin{aligned}
& \text { Armalcolita }-(\mathrm{Mg}, \mathrm{Fe}) \mathrm{Ti}_{2} \mathrm{O}_{5}-\text { ortorrômbico } \\
& \text { Tranqüilidita }-\mathrm{Fe}_{8}\left(\mathrm{Zr}_{\mathrm{Y}}, \mathrm{Y}_{2} \mathrm{Ti}_{3} \mathrm{Si}_{3} \mathrm{O}_{24}-\right.\text { hexagonal } \\
& \text { Piroxferroíta }-(\mathrm{Ca}, \mathrm{Fe})(\mathrm{Fe}, \mathrm{Mn})_{6}\left(\mathrm{Si}_{7} \mathrm{O}_{21}\right)-\text { triclínico }
\end{aligned}
$$

Três minerais são de especial interesse não só científico como também para a história da mineralogia: armalcolita, tranqüilidita e piroxferroíta (Embrey e Fuller 1980). Os três, apesar de pertencerem a classes ou grupos distintos, têm em comum a mesma procedência, pois constituem espécies encontradas originalmente na Lua, de onde foram trazidas pelas missões espaciais norteamericanas Apolo XI e Apolo XII, no final da década de 1960.

A armalcolita é um mineral semelhante à pseudobrookita, mas com ferro divalente. É cinza, opaco e forma grãos geralmente de contorno retangular, com 0,1-0,3 mm na maior dimensão. Encontra-se comumente intercrescido com ilmenita, possuindo peso específico 4,94. A tranqüilidita ocorre em rochas basálticas, onde forma cristais micrométricos quase opacos, de peso específico 4,7 associados com feldspato alcalino, cristobalita, piroxferroíta e troilita, desenvolvendo-se nos últimos estágios de cristalização do magma. A piroxferroíta, um piroxenóide amarelo (Fig. 4a), forma uma série isomórfica com a piroxmanguita, constituindo pequenos agregados em microgabros ou diabásios junto com clinopiroxênio, plagioclásio e ilmenita. Posteriormente, armalcolita e piroxferroíta foram também encontrados na Terra.

\section{Lonsdaleíta e chaoíta - C - hexagonais}

O diamante, embora reconhecido há mais de 2.000 anos na Índia, teve sua constituição química identificada como carbono puro somente no século XVIII pelo célebre cientista francês Lavoisier, ao calcinar uma amostra do mineral e verificar que o gás resultante do processo era o $\mathrm{CO}_{2}$. Diamantes cristalizam no sistema cúbico e o outro polimorfo comum do mesmo elemento, a grafita (sistema hexagonal), foi também identificada há muitos séculos. Entretanto, existem dois outros polimorfos constituídos de carbono na forma hexagonal lonsdaleíta e chaoíta - de descrições relativamente mais recentes, que possuem modos peculiares de formação, uma vez que resultam de fenômenos com influências extraterrestres. Não obstante, ainda existem controvérsias interessantes a respeito desses minerais, conforme será discutido a seguir.

Hanneman et al. (1967) descreveram "diamantes hexagonais" no meteorito férrico Canyon Diablo, encontrado na cratera Meteor, em Coconino, Arizona (EUA) ${ }^{1}$. Frondel e Marvel (1967) descreveram esse material com o nome de lonsdaleíta, que foi logo aprovado pela IMA (Fleischer 1967). As circunstâncias então verificadas indicavam que o mineral poderia ter se formado por conversão de fase a partir de diamante, durante o choque do bólido extraterrestre com a superfície do planeta. Quase na mesma época, El Goresy e Donnay (1968) identificaram um material semelhante, aparecendo como lamelas na grafita na cratera Ries, em Möttingen, região da Bavária (Alemanha). Nesse local, o impacto do meteorito teria ocorrido contra grafitagnaisses, e assim, naturalmente foi suposto que o mineral se formaria pela transformação da grafita presente naquelas rochas crustais.

Paralelamente, El Goresy (1969) designou esse último material como chaoíta (Fig. 4b), nome aprovado pela IMA, embora com restrições (Fleischer 1969). Observando-se a simetria cristalina de ambos os minerais e seus modos de formação, desconfia-se de imediato que eles possam constituir uma única espécie. Lonsdaleíta e chaoíta foram descritas originalmente em revistas "concorrentes":

1 Interessante lembrar que um dos primeiros estudos mineralógicos sobre esse meteorito foi efetuado pelo "pai" da geologia brasileira, Orville A. Derby, que inclusive fez comparações entre o mesmo com o meteorito "Bendengó", encontrado na Bahia (Derby 1895), e hoje exposto no Museu Nacional do Rio de Janeiro. 
a primeira na Nature e a outra na Science, as quais não iriam abrir mão da prioridade de suas descobertas. Fica assim a questão - um ou dois minerais - que necessita ainda de estudos esclarecedores. A estrutura cristalina hexagonal "compactada" dos mesmos, na realidade uma fase transitória entre diamante e grafita, permite que eles (ou ele) em princípio possam se formar a partir de qualquer um desses dois minerais. No entanto, na listagem oficial da IMA (2006), ambas as espécies encontramse regularmente aprovadas.

\section{Diamante carbonado - C-cúbico}

Embora na atualidade a maioria dos processos termodinâmicos que levam à formação do diamante no manto terrestre esteja razoavelmente bem esclarecida (eg., Bulanova 1995), de modo contrário uma de suas variedades, o carbonado, tem ainda sua gênese alvo de intensos debates e muitas controvér-


Figura 4 - Fotos ilustrativas de minerais que podem se associar a fenômenos ou processos extraterrestres, como a (a) piroxferroíta (Japão), (b) chaoíta (Cratera Ries, Alemanha) e (c) carbonado (Serra do Espinhaço, Minas Gerais, Brasil). Fotos (a) e (b) de Weissman e Nikischer (1999), e foto (c) de Chaves e Brandão (2004) sias. O carbonado é uma variedade policristalina incomum do diamante, de cor cinza-escura ou preta, de aspecto feio e irregular, apresentando alta porosidade (Fig. 4C). Um grande número de minerais diferentes, muitos deles de origem crustal, bem como ligas metálicas complexas, já foram identificadas como inclusões nos carbonados. Nesse material, os cristalitos de diamante atingem as menores proporções naturalmente conhecidas (menores que 20 micra de diâmetro), sendo que essas dimensões ínfimas têm estimulado incessantes pesquisas a fim de produzir material sintético similar, que teria forte aplicação na indústria de materiais abrasivos.

Em Chaves e Brandão (2004), encontra-se uma síntese dos diferentes modelos genéticos já propostos para explicar a formação dos carbonados: (1) impacto de bólidos extraterrestres sobre rochas carbonáceas; (2) influência direta de radioatividade crustal sobre rochas ricas em carbono; (3) em dois estágios, com a formação dos cristalitos no manto, colocação dos mesmos na crosta durante magma-

tismo kimberlítico ou lamproítico, e a posterior agregação desses cristalitos na superfície terrestre, em meio radioativo; (4) stress hidrodinâmico gerado acusticamente por uma grande explosão na crosta.

$\mathrm{Na}$ região da Serra do Espinhaço, em Minas Gerais e Bahia, onde tal variedade foi descrita pela primeira vez na literatura e que constitui a maior produtora do material a nível mundial, os citados autores apontam a terceira hipótese, acima mencionada, como a mais plausível de ser suportada pelo conhecimento geológico atualmente disponível para aquela região. Entretanto, os mesmos autores admitem que ainda se está longe de conhecer, de fato, todas as condições que levaram ao desenvolvimento desse estranho material carbonoso, e assim as influências extraterrestres não podem ser descartadas. Na verdade, para a Geologia o carbonado deveria ser considerado uma rocha (e não uma variedade mineral) constituída de diamantes - e assim ser melhor designado como um "diamantito". 


\section{Considerações finais}

$\mathrm{O}$ estudo de novos minerais, mesmo sendo a maioria deles raríssimos na natureza, ou de gênese peculiarmente exótica, tem constituído um desafio para a nova geração de mineralogistas. Sem dúvidas, diversos centros de pesquisa internacionais dedicam-se a tal intento, por motivos tão variados como o desenvolvimento tecnológico de novos materiais, a obtenção do diamante sob baixas condições de temperatura/pressão, ou mesmo a cura de certas doenças. Ressalta-se assim o fato de que a Mineralogia e seus conhecimentos gerados devem permanecer constituindo, como sempre foram, a verdadeira base fundamental das ciências geológicas.

\section{Agradecimentos}

O co-autor (MLSCC) agradece à FAPEMIG Fundação de Amparo à Pesquisa de Minas Gerais, pelo apoio a diversos projetos de pesquisa na área de Mineralogia básica e aplicada, desenvolvidos ao longo dos últimos anos no IGC/UFMG (Processos EDT-2244/05, CRA-443/04 e CRA-582/02).

\section{Referências bibliográficas}

Aljubouri Z.A, Aldabbagh S.M. 1980. Sinjarite, a new mineral from Iraq. Mineral. Mag., 43:6443-6645.

Atencio D., Carvalho F.M.S., Matioli P.A. 2004a. Coutinhoite, a new thorium uranyl silicate, from Urucum mine, Galiléia, Minas Gerais, Brazil. Am. Mineral., 89:721-724.

Atencio D., Coutinho J.M.V., Graeser S., Matioli P.A., Menezes Filho L.A. 2004b. Lindbergite, a new $\mathrm{Mn}$ oxalate dihydrate from Boca Rica mine, Galiléia, Minas Gerais, Brazil, and other occurrences. Am. Mineral., 89:1087-1091.

Atencio D. 2004. Coutinhoíta e lindbergita: mineralogia aplicada. In: CONGRESSO Brasileiro de Geologia, 42, Anais, Araxá (MG), S25-T24 (CDROM).

Bulanova G.P. 1995. The formation of diamond. J. Geoch. Explor., 53:1-23.

Chaves M.L.S.C., Brandão P.R.G. 2004. Diamante variedade carbonado na Serra do Espinhaço (MG/BA) e sua enigmática gênese. REM - Rev. Esc. Minas, 57:33-38.

Derby O.A. 1895. Constituents of the Canon Diable meteorite. Am. J. Sci., XLIX:101-110.
El Goresy A., Donay G. 1968. A new allotropic form of carbon from the Ries crater. Science, 161:363364.

El Goresy A. 1969. Eine neue KohlnestoffModifikation aus dem Nördlinger Ries. Naturwissenschaften, 56:493-494.

El Goresy A., Chao E.C.T. 1976. Identification and significance of armalcolite in the Ries glass. Earth. Planet. Sci. Letters, 30:200-208.

Embrey P.G., Fuller J.P. 1980. A manual of new mineral names 1892-1978. London: British Museum, 467p.

Evans H.T., Berner R.A., Milton C. 1962. Valleriite and macknawite. In: 1962 Ann. Meet. Geol. Soc. Am., Proceed., p.25, Houston (Texas).

Fleet M.E. 1975. The crystal structure of paratacamite, $\mathrm{Cu}_{2}(\mathrm{OH})_{3}$ Cl. Acta Cryst., B31:183-187.

Fleischer M. 1963. New mineral names. Mackinawita. Am. Mineral., 48:511.

Fleischer M. 1967. New mineral names. Lonsdaleíta. Am. Mineral., 52:1579.

Fleischer M. 1969. New mineral names. Am. Mineral., 54:326.

Fleischer M., Chao G.Y., Mandarino J.A. 1976. New mineral names. Acetamide. Am. Mineral., 61:338.

Gibson R. I. 1974. Descriptive human pathological mineralogy. Am. Mineral., 59:1177-1182.

Hurlbut Jr. C.S., Aristarain L.F., Erd R.C. 1977. Hydrochlorborite from Antofagasta, Chile. Am. Mineral., 62:147-150.

Guild F.N. 1920. Flagstaffita, a new mineral from Arizona. Am. Mineral., 5:169-172.

Hanneman R.E., Strong H.M., Bundy F.P. 1967. Hexagonal diamonds in meteorites. Science, 155:995-997.

IMA - International Mineralogical Association. 2006. $<$ www.ima-mineralogy.org > . Último acesso: 04/12/2006.

Mandarino J.A., Back M.E. 2004. Fleischer's Glossary of Mineral Species 2004. Tucson: Mineralogical Record, 309p.

Martini J. 1978. Sasaite, a new phosphate mineral from West Driefontein Cave, Transvaal, South Africa. Mineral. Mag., 42:401-404.

Milton C., Axelrod J. 1947. Fused wood-ash stones: fairchildite (n.sp.) $\mathrm{K}_{2} \mathrm{CO}_{3} \mathrm{CaCO}_{3}$, bütschliite (n.sp.) $3 \mathrm{~K}_{2} \mathrm{CO}_{3} \cdot 2 \mathrm{CaCO}_{3} \cdot 6 \mathrm{H}_{2} \mathrm{O}$ and calcite, their essential components. Am. Mineral., 32:607-624. 
Nickel E.N., Grice J.D. 1998. Comissão de novos minerais e nomes de minerais da IMA: procedimentos e diretrizes sobre nomenclatura mineralógica, 1998. Rev. Bras. Geoc., 28:229-242 (tradução de D. Atencio).

Nickel E.N., Nichols M.C. 1991. Mineral Reference Manual. New York: Van Nostrand Reinhold, 250p.

Organ R.M., Mandarino J.A. 1971. Romarchite and hydroromarchite, two new stannous minerals. Can. Mineral., 10:916.

Pring A. 1994. Are new minerals useful? In: $16^{\text {th }}$ General Meeting IMA, Italy, p.339.

Shebrodol'skii B.I. 1975. Acetamide, $\mathrm{CH}_{3} \mathrm{CONH}_{2}$, a new mineral. Zapiski Vses. Mineral. Obshch., 104:326-328 (in russian).

Sterling C. 1965. Crystal-structure analysis of weddelite, $\mathrm{CaC}_{2} \mathrm{O}_{4}(2+\mathrm{x}) \mathrm{H}_{2} \mathrm{O}$. Acta Cryst., A18:917-921.

Strunz H., Contag B. 1965. Evenkit, Flagstaffit, Idrialin und Reficit. Neues Jahrb. Mineral., Monatsh. 1:19-25.

Encontros
Tassel R.V. 1958. On the crystallography of calclacite, $\mathrm{Ca}\left(\mathrm{CH}_{3} \mathrm{COO}\right) \mathrm{Cl} \cdot 5 \mathrm{H}_{2} \mathrm{O}$. Acta Cryst., A11:745746.

Torii T., Ossaka J. 1965. Antarcticite: a new mineral, calcium chloride hexahydrate, discovered in Antarctica. Science, 149:975-977.

Weissman J.G., Nikischer A.J. 1999. Photographic Guide to Mineral Species. New York: Excalibur Mineral Corp., CD-ROM.

Whitaker A., Jeffery J.W. 1970. The crystal structure of struvite, $\mathrm{MgNH}_{4} \mathrm{PO}_{4} \cdot 6 \mathrm{H}_{2} \mathrm{O}$. Acta Cryst., B26:1429-1440.

Williams S.A. 1972. Embreyite, a new mineral from Berezov, Siberia. Mineral. Mag., 38:790-793.

Wilson, M.J., Jones, D., Russel J.D. 1980. Glushinskite, a naturally occurring magnesium oxalate. Mineral. Mag., 43:837-840.

Wilson M.J., Jones D. 1984. The occurrence and significance of manganese oxalate in Pertusaria corallina (Lichenes). Pedobiologia, 26:373-379.

\section{ENCONIROS DO Fó RUM Nacional de CURSOS DE GEOLOGIA}

\section{Encontros}

O Fórum Nacional de Cursos de Geologia foi criado em Campinas (SP), em abril de 2002, durante a segunda reunião de coordenadores de cursos de graduação em Geologia. A primeira reunião dessa natureza ocorreu em Salvador, em maio do ano de 2001. A partir de então, o Fórum promoveu sucessivos encontros nos locais e anos / meses a seguir indicados: 1. 2002 / setembro - João Pessoa (PR)

2. 2003 / maio/junho - Belém (PA)

3. 2004 / junho - Diamantina (MG)

4. 2004 / outubro - Araxá (MG)

5. 2005 / junho - Cuiabá (MT)

6. 2006 / junho - Rio de Janeiro (RJ) s/n 2006 / setembro - Aracaju (SE)

Estão marcadas as seguintes reuniões:

7. 2007 / maio - São Paulo (SP) 2008 / novembro - Curitiba (PR)

\section{Relatos}

Textos dos encontros que antecederam a criação do Fórum publicados na revista Terræ Didatica:

Sobreira F. 2005. Relato Final do I Seminário Nacional sobre Cursos de Graduação em Geologia. Salvador, maio de 2001. Terræ Didatica, 1(1):51-54. <http://www.ige.unicamp.br/terraedidatica/> .

Carneiro C.D.R. 2005a. Relato Final do II Seminário Nacional sobre Cursos de Graduação em Geologia. Campinas, abril de 2002. Terræ Didatica, 1(1):55-63. <http://www.ige.unicamp.br/terraedidatica/>.

Relatos de encontros do Fórum publicados na revista Terrae Didatica: Carneiro C.D.R. 2005. Relato Final do I Encontro do Fórum Nacional de Cursos de Geologia. João Pessoa, setembro de 2002. Terræ Didatica, 1(1):70-73. <http://www.ige.unicamp.br/terraedidatica/> Carneiro C.D.R., Assis J.F.P. 2005. Relato Final do II Encontro do Fórum Nacional de Cursos de Geologia. Belém, maio de 2003. Terræ Didatica, 1(1):74-83. <http://www.ige.unicamp.br/terraedidatica/>.

Carneiro C.D.R., Nummer A.R., Assis J.F.P., Pinho F.E.C. 2005. Relato Final do III Encontro do Fórum Nacional de Cursos de Geologia. Diamantina, junho de 2004. Terræ Didatica, 1(1):84-96.

$<$ http://www.ige.unicamp.br/terraedidatica/>

Estão incluídos neste número de 2006 da revista Terrae Didatica os seguintes relatos de encontros do Fórum:

Carneiro C.D.R., Assis J.F.P. 2006. Relato Final do IV Encontro do Fórum Nacional de Cursos de Geologia. Araxá, outubro de 2004. Terræ Didatica, 2(1):86-90. < http://www.ige.unicamp.br/terraedidatica/>. Assis J.F.P., Lazzarotto A. 2006. Relato Final do V Encontro do Fórum Nacional de Cursos de Geologia. Cuiabá, junho de 2005. Terræ Didatica, 2(1):91-104. < http://www.ige.unicamp.br/ terraedidatica/> . 